\section{REVIEW ARTICLE}

\author{
Nicholas H. Mann \\ Tel: +44203 523526. Fax: +44203 523701. e-mail: nm@dna.bio.warwick.ac.uk \\ Department of Biological Sciences, University of Warwick, Coventry CV4 7AL, UK
}

\title{
Protein phosphorylation in cyanobacteria
}

Keywords: cyanobacteria, protein phosphorylation, nutrient acquisition, thylakoids

\section{Prologue}

The post-translational modification of proteins by phosphorylation may take a variety of forms, but in essence it is always a component of a process of adaptation that enables cells to sense and respond to changes in their external or internal environments. This review presents evidence that not only do the various forms of protein phosphorylation occur in the cyanobacteria, but that they are central to many of the adaptive responses exhibited by these organisms (for review see Tandeau de Marsac \& Houmard, 1993) and, indeed, may play a key role in the integration of metabolism. Early studies on protein phosphorylation in prokaryotes were largely confined to phosphate monoester formation with hydroxyl-containing amino acid residues. It was originally thought that protein acyl phosphates and amido phosphates only occurred as intermediates of enzyme catalysis. However, it is now clear that these forms of protein phosphorylation are of enormous significance in the process of sensory transduction via two-component sensory systems involving members of the conserved histidine protein kinase and response regulator families of proteins (for reviews see Stock et al., 1989; Parkinson \& Kofoid, 1992).

The dominant nutritional mode of cyanobacteria is photoautotrophy, and thus growth, with its reliance on light as the primary energy source, proceeds via the fixation of $\mathrm{CO}_{2}$ and the acquisition of other simple inorganic nutrients. This would lead one to suggest that the central adaptive responses of these organisms might be to environmental variables such as the intensity and spectral quality of light, coupled with the availability of key inorganic nutrients. A potentially lethal consequence of their phototrophic lifestyle is the risk of photoinhibition, when the rate at which light energy is harvested exceeds the rate at which it can be converted into useful metabolic energy. This emphasizes the importance of inorganic nutrients, since limitation for one or more greatly increases the non-productive excitation of photosynthetic reaction centres and photoinhibition may be greatly increased. Furthermore, under conditions where $\mathrm{CO}_{2}$ fixation is restricted, photosynthetic electron transport may lead to the extensive production of superoxide radicals with the potential for extensive oxidation damage to the cell. These factors emphasize the critical importance to the physiology of cyanobacteria of integrating the central metabolic process of light harvesting with inorganic nutrient acquisition and consequently this review also examines the possible role of protein phosphorylation in this process of integration.

\section{Evidence for protein phosphorylation}

There are several reports which describe the in vivo labelling of polypeptides, using $\left[{ }^{32} \mathrm{P}\right]$ orthophosphate, in various species of cyanobacteria, including Synechococcus sp. PCC 6301 (Allen et al., 1985), Calotbrix sp. PCC 7601 (Schuster et al., 1984), Anabaena sp. PCC 7120 (Mann et al., 1991), Synechocystis sp. PCC 6803 (Bloye et al., 1992; Hagemann et al., 1993) and Synechococcus sp. PCC 7942 (Forchhammer \& Tandeau de Marsac, 1994). Such studies reveal of the order of 10 labelled polypeptides, but this must be taken as very much a minimum number since only the most abundant phosphoproteins would be discovered by such an approach and, furthermore, only polypeptides phosphorylated as monoesters would have been detected by the methods employed. An additional caveat which must be borne in mind when assessing the results obtained using this approach is that in addition to phosphorylation, other forms of protein modification may be detected, such as ADP-ribosylation and adenylylation. A complementary approach to the in vivo labelling of cells with ${ }^{32} \mathrm{P}$-orthophosphate has been to study protein phosphorylation at the expense of $[\gamma-$ $\left.{ }^{32} \mathrm{P}\right]$ ATP in vitro. Such experiments have been carried out with cell-free extracts from Calothrix sp. PCC 7601 (Schuster et al., 1984), Synechococcus sp. PCC 6301 (Allen et al., 1985), Anabaena sp. PCC 7120 (Mann et al., 1991) and Synechocystis sp. PCC 6803 (Bloye et al., 1992; Hagemann et al., 1993) and numerous phosphorylated polypeptides detected. The caveat with this approach is that while only the phosphorylation of proteins is detected, many more polypeptides become labelled than can be detected by the in vivo approach and, thus, there must be concern that the phosphorylation of some of these polypeptides may be artifactual and has no genuine physiological significance. 


\section{Light}

Cyanobacteria, like higher plants, exhibit oxygenic photosynthesis and possess two distinct photosystems with associated protein complexes within the thylakoid membranes, which are usually quite distinct from the cytoplasmic membrane. Chlorophyll $a$ is involved in the reaction centres of both photosystems, but cyanobacteria lack light-harvesting complex II (LHCII) and, instead, phycobiliproteins, organized into macromolecular complexes known as phycobilisomes, represent the primary light harvesting antennae (for review see Grossman et al., 1993). Cyanobacteria are capable of responding to changes in both the intensity and spectral quality of light and protein phosphorylation has been implicated in the response to spectral quality. Among the cyanobacterial responses to changes in spectral quality are state transitions, which involve a redistribution of excitation energy between PSI (photosystem I) and PSII (photosystem II), and chromatic adaptation, in which the complement of light-harvesting phycobiliproteins becomes modified. Both processes enable the organism to optimize its photosynthetic capacity in response to a particular regime of illumination.

\section{Thylakoid phosphoproteins}

Since much of the scientific interest in cyanobacteria is focused on their photosynthetic processes, it follows that many analyses of the roles of protein phosphorylation in cyanobacteria have been concerned with the organisms' responses to light, but only in very few cases have known components of the photosynthetic complexes been unambiguously identified as being subject to phosphorylation. In higher plants the $p s b H$ gene product, a component of PSII, is known to be phosphorylated on a threonine residue at position 2 in the polypeptide, but the cyanobacterial PsbH lacks the phosphorylation site (see Allen, 1992). However, Race \& Gounaris (1993) have established immunologically that the Synechocystis sp. PCC: 6803 psbH gene product is present in the thylakoid as a $6 \mathrm{kDa}$ phosphoprotein. Harrison (1990) has tentatively identified the $\beta$-phycocyanin as a phosphoprotein in Synechococcus sp. PCC 6301 following in vivo labelling with $\left[{ }^{32} \mathrm{P}\right]$ orthophosphate, extensive protein purification and amino-terminal sequencing of an $18.5 \mathrm{kDa}$ phosphoprotein. In this laboratory (unpublished results) in vitro labelling experiments using cell-free extracts of Synechocystis sp. PCC 6803 have led to the same conclusion. However, though few specific thylakoid proteins have been reported as being subject to phosphorylation, there is considerable evidence of a less direct nature that a number of thylakoid and/or phycobilisome proteins are subject to phosphorylation. A variety of in vitro labelling experiments using $\left[\gamma^{32} \mathrm{P}\right]$ ATP have indicated the phosphorylation of thylakoid proteins in thylakoid preparations, of greater or lesser purity, from Calothrix sp. PCC 7601 (Schuster et al., 1984), Synechococcus sp. PCC 6301 (Allen et al., 1985), Synechococcus sp. PCC 7942 (James et al., 1992) and Synechocystis sp. PCC 6803 (Bloye et al., 1992). In vivo labelling studies using white-light-grown Calothrix sp. PCC 7601 cells revealed the phosphorylation of three thylakoid proteins on serine or threonine residues (Schuster et al., 1984). Similar experiments with Synechococcus sp. PCC 6301 revealed the light-dependent phosphorylation of a $15 \mathrm{kDa}$ polypeptide exclusively associated with the membranes and a predominantly cytoplasmic polypeptide of $18.5 \mathrm{kDa}$ (Allen et al., 1985). The $18.5 \mathrm{kDa}$ protein could also be found in a purified phycobilisome fraction after in vivo labelling of Synechococcus sp. PCC 6301 cells (Sanders \& Allen, 1987) and presumably, on the basis of the results of Harrison (1990), may be $\beta$-phycocyanin.

\section{State transitions}

Cyanobacteria, like higher plants, are capable of shortterm responses to fluctuations in the spectral quality of incident light that lead to an imbalance in the energy harvested by PSI and PSII. These state transitions result in a readjustment of the distribution of excitation energy between the two photosystems so as to minimize the imbalance. The regulation of light-induced state transitions in cyanobacteria and the associated phosphorylation of thylakoid proteins has amassed a very considerable and, at times, contradictory literature, which could not be dealt with in this short review. Fortunately this topic has recently been the subject of an excellent and detailed treatment by Allen (1992). The essence of the debate concerns the models which have been proposed to explain two key aspects of the state transitions, namely control of the process and the mechanism of energy redistribution. As regards control of the process it is variously proposed that the control of state transitions are determined by (i) the redox state of components of the intersystem chain, (ii) localized electron gradients around PSI and PSII, and (iii) cyclic electron flow around PSI. The opposing ideas concerning energy redistribution centre round spill-over from PSII to PSI or redirection of energy harvested by the phycobilisome directly to PSI. Furthermore, although several thylakoid membrane proteins are subject to phosphorylation both in vivo and in vitro, correlative rather than direct evidence implicates protein phosphorylation in the state transition process. In addition to the information reviewed by Allen (1992), it has been shown more recently in the case of Synechococcus sp. PCC 7942 (Forchhammer \& Tandeau de Marsac, 1994) that the in vivo phosphorylation of certain polypeptides was influenced by the spectral quality of the light used for growth. Before leaving this topic it is important, for reasons relating to the crucial relationship between light harvesting and inorganic nutrient acquisition, to note that state transitions, and/or closely related phenomena, may not be exclusively determined by the spectral quality of the irradiance and that nitrogen metabolism, inorganic carbon $\left(C_{i}\right)$ limitation and salt stress have all been shown to be involved (see below).

\section{Chromatic adaptation}

In cyanobacteria the light-harvesting antenna pigments for PSII are the phycobiliproteins, primarily phycocyanin, phycoerythrin and allophycocyanin, organized as 
components of the phycobilisome. Many cyanobacteria, though not all, exhibit an ability to alter the phycobiliprotein composition of their phycobilisomes in response to the spectral quality of the incident illumination, a process known as chromatic adaptation (for reviews see Grossman et al., 1993; Tandeau de Marsac \& Houmard, 1993). Group I organisms do not alter their phycobiliprotein composition, whereas group II organisms alter the abundance of phycoerythrin. In group III organisms such as Fremyella diplosiphon, complementary chromatic adaptation occurs, in which red light promotes the synthesis of an inducible phycocyanin $\left(\mathrm{PC}_{\mathbf{i}}\right)$ and represses the synthesis of phycoerythrin, whereas green light stimulates the synthesis of phycoerythrin and represses the synthesis of $P C_{i}$. Accumulation of the different phycobiliproteins is a direct reflection of transcript abundance.

Sobczyk et al. (1993) have identified factors that interact with the promoter region of the phycoerythrin operon. Two proteins (designated RcaA and RcaB) were found only in extracts of cells of Calothrix sp. PCC 7601 grown under green light and appeared to behave as positive transcriptional activators of the $c p e B A$ (phycoerythrin) operon. The ability of RcaA, but not RcaB, to bind to the promoter region was lost upon treatment with alkaline phosphatase, strongly suggesting that the binding activity of RcaA was phosphorylation dependent. The RcaA binding site contained the motif TTGTTA-N ${ }_{4}$ TTGTTA. A protein (PepB) with the same binding specificity was detected by Schmidt-Goff \& Federspiel (1993), but PepB appeared to be present under both red and green light and no information is available on whether PepB is subject to phosphorylation. Sobczyk (1994) suggests that the discrepancy between these results may possibly be explained by differences in culture conditions and by the fact that the SF33 strain used by Schmidt-Goff \& Federspiel (1993) is a mutant of Calothrix sp. PCC 7601. Another protein (RcaD), which could only be isolated from red-light-grown cells, bound to the promoter region of the red-light-induced $c p c B 2 A 2 H 2 I 2 D 2$ operon, also in an apparently phosphorylation-sensitive fashion (Sobczyk et al., 1994).

Chiang et al. (1992) have characterized a gene, $r c a C$, which complements a mutation in $F$. diplosiphon that causes the organism to be unable to respond to red light. 'The polypeptide encoded by $\mathrm{rca} C$ is thought to be a negative regulator and is unusual since it exhibits two regions of strong similarity to the response regulator family of proteins, including the two potential phosphorylation sites; in this sense it resembles FrzZ of Myxococcus xantbus (see Parkinson \& Kofoid, 1992). Chiang et al. (1992) point out that its $\mathrm{N}$-terminus (extending up to approximately residue 240) exhibits similarity to the $\mathrm{N}$-terminus of Bacillus subtilis PhoP. The C-terminal domain of $\mathrm{RcaC}$ (extending from approximately residue 530 to 633) exhibits strong similarity to the C-terminus of Escherichia coli $\mathrm{CreB}$, also a response regulator. We have also noted a region (130 residues) of lower similarity (20.8\%) to SscC (resolvase integrase) in the intervening domain. Another mutant, FdB1, of $F$. diplosiphon, which exhibits con- stitutive synthesis of $\mathrm{PC}_{\mathrm{i}}$, has been complemented by a fragment of genomic DNA containing three ORFs, two of which encode polypeptides exhibiting strong homologies to the $E$. coli histidine protein kinase $\mathrm{NR}_{\mathrm{II}}$. The third ORF exhibits homology to rat myosin light-chain kinase (Grossman et al., 1993). The role of these kinases, however, is still open to doubt since re-complementation of the mutant with the DNA fragment carrying these ORFs was not successful. This evidence for a phosphorylation cascade, modulated by photo-perception, controlling complementary chromatic adaptation has been incorporated into a model described in full in the review by Grossman et al. (1993).

Most cyanobacteria also exhibit inverse chromatic adaptation in which under PSII light there is a relative increase in PSI components and a decrease under PSI light (see Tandeau de Marsac \& Houmard, 1993). In vivo labelling of Synechococcus sp. PCC 6301 cells revealed enhanced phosphorylation, under PSII light, of a $19 \mathrm{kDa}$ polypeptide in the phycobilisome fraction (Sanders et al., 1989). Harrison (1990) established that $\beta$-phycocyanin is subject to phosphorylation in vivo and suggested that the redox control of $\beta$-phycocyanin phosphorylation on a tyrosine residue may be involved in a photoreceptor mechanism involved in modulating long-term changes in the composition of the photosynthetic complexes and that the phosphorylation produces a photochromic form of the pigment. Such a model would be consistent with the changes involved in inverse chromatic adaptation. Indeed, it is worth noting that sequence analysis of a $14.9 \mathrm{~kb}$ fragment of DNA from Synechococcus sp. WH8020 encoding the major phycobiliprotein rod components revealed a partial ORF, adjacent to $r p c F$, which would encode a predicted polypeptide exhibiting homology to the $\mathrm{N}$-terminal sequence of a low molecular mass cytosolic acid phosphatase from bovine liver (Wilbanks \& Glazer, 1993). The liver enzyme shows phosphotyrosine phosphatase activity and a particular feature of the homology is a 12 residue stretch of identical amino acids between the two proteins believed to be the active site of the bovine enzyme. The polypeptide encoded by this ORF could be a candidate for a phosphatase controlling the suggested tyrosine phosphorylation of $\beta$-phycocyanin.

\section{Inorganic nutrients}

\section{$\boldsymbol{C}_{\boldsymbol{i}}$}

Quantitatively $\mathrm{CO}_{2}$ is the most important inorganic nutrient for cyanobacteria and it frequently becomes the limiting nutrient, during periods of high insolation, in the surface layers of freshwater environments which have a significant cyanobacterial population. In the presence of $\mathrm{O}_{2}$, cyanobacterial ribulose-1,5-bisphosphate carboxylase/oxygenases exhibit a relatively low affinity (effective $K_{\mathrm{m}}$ approximately $600 \mu \mathrm{M}$ ) for $\mathrm{CO}_{2}$ (Pierce \& Omata, 1988) and under conditions of low $\mathrm{CO}_{2}$ concentration many species induce a bicarbonate-concentrating system (see Badger, 1987; Miller, 1990). Following a shift from bicarbonate-limited conditions to excess bicarbonate supply, Synechocystis sp. PCC 6803 exhibited a 
rapid reduction in bicarbonate uptake rate and this was accompanied by the phosphorylation of a number of polypeptides ranging in size from $15-70 \mathrm{kDa}$ (Bloye $e$ al., 1992). Similar changes in the profile of phosphorylated polypeptides were also observed when bicarbonatelimited cultures were shifted into the dark or were provided with exogenous glucose. Matching patterns of phosphorylation were obtained in vitro using the membrane fraction. Further studies (unpublished results - this laboratory) have localized the majority of these phosphorylated membrane proteins to the thylakoid fraction and it may be that some of these changes in the pattern of protein phosphorylation are associated with a loss of the partially uncoupled state of PSII, which is a characteristic of the $\mathrm{C}_{\mathbf{i}}$-limited condition (Miller \& Canvin, 1987). In keeping with this is the observation that $\mathrm{CO}_{2}$ transport was driven by ATP produced by cyclic or pseudocyclic photophosphorylation (Miller et al., 1988) and the response to $C_{i}$ availability might represent a nutritionally induced state transition. Thus $C_{i}$ limitation may induce a transition to state 2 , which would favour the ATP production required to energize $C_{i}$ concentration.

\section{Nitrogen metabolism and heterocyst formation}

Nitrogen is quantitatively the second most important inorganic nutrient for cyanobacteria. Nitrate and ammonium, as well as a range of other inorganic and organic nitrogen sources, are utilized, and many species, including some unicellular strains, are capable of fixing dinitrogen. Furthermore, when nitrate is the nitrogen source for growth there will be a significantly increased demand for reductant in competition with photosynthetic $\mathrm{CO}_{2}$ fixation. Anacystis nidulans strain 1402-1 cells exhibited stimulation of non-cyclic electron flow in response to nitrate, presumably in response to enhanced demand for reductant (Romero \& Lara, 1987). The same organism exhibited non-photochemical fluorescence quenching, resembling a state 1 transition, in response to ammonium, but not nitrate (Romero et al., 1992). A $13 \mathrm{kDa}$ protein in Synechococcus sp. PCC 6301 was shown to become labelled with $\mathrm{P}_{\mathrm{i}}$ in vivo exclusively under PSII light; subsequent purification and $\mathrm{N}$-terminal sequencing revealed it to have strong homology to the $G \ln B\left(P_{I I}\right.$ protein) of $E$. coli (see Allen, 1992). In E. coli GlnB is subject to uridylylation as a response to decreasing glutamine concentration relative to 2-oxoglutarate concentration and in turn activates an adenylyltransferase which deadenylylates glutamine synthetase causing its activation. Uridylylation of GlnB also serves, by a cascade of phosphorylation reactions, to lead to transcription of the $\sigma^{54}$-dependent gln $A L G$ operon resulting in increased de novo synthesis of glutamine synthetase (for review see Magasanik, 1988). Using probes based on this N-terminal sequence information, Tsinoremas et al. (1991) cloned and sequenced a glnB homologue from Synecbococcus sp. PCC 7942 and demonstrated that the in vivo modifying group was sensitive to phosphodiesterase, consistent with uridylylation. The modification state of the cyanobacterial GlnB homologue in Synechococcus sp. PCC 6301 was shown to be sensitive not only to ammonium ion concentration, but also to light quality (Tsinoremas et al., 1991). Incubation under light exciting PSII increased the degree of modification. Thus, it was proposed that photosynthetic electron transport might regulate nitrogen assimilation via the modification state of the $G \ln B$ protein.

Recently, Forchhammer \& Tandeau de Marsac (1994) have shown that the GInB protein of Synechococcus sp. PCC 7942 is not in fact uridylylated, rather it is phosphorylated on a serine residue. It appears that the cyanobacterial $\mathrm{G} \ln \mathrm{B}$ protein is a trimer and consequently can potentially exist in four states, ranging from unphosphorylated to all three subunits phosphorylated. These studies, however, conflict with earlier studies regarding the effect of light quality. Forchhammer \& Tandeau de Marsac (1994) found that the nitrogen status of the cell was the primary determinant of $\mathrm{GlnB}$ modification and that light-dependent variations were mediated through nitrate metabolism. The apparently contradictory results may reflect physiological differences between the strains used.

There is indirect evidence for protein phosphorylation playing a role in heterocyst pattern formation. Liang et al. (1992) isolated a mutant (PAT-1) of Anabaena sp. PCC 7120 exhibiting an altered pattern of heterocyst formation and poor growth under nitrogen-fixing conditions. The wild-type gene pat $A$, which complements the lesion in the mutant, encodes a 379 amino acid polypeptide consisting of three domains. The carboxyl-terminal domain exhibits considerable homology to the response regulator $\mathrm{CheY}$.

\section{Phosphate}

Phosphate is quantitatively the next most important inorganic nutrient for cyanobacteria after nitrogen, but in fact is more commonly the limiting nutrient in many freshwater environments. It has been suggested, as a result of studies on phosphate acquisition by Synechococcus sp. PCC 6301, that the uptake system may respond to changes in the external phosphate concentration by some form of sensory system (Falkner et al., 1989). Indeed, there is now rapidly increasing evidence for a response to restricted phosphate availability which involves components exhibiting a marked similarity to the key elements of the extensively characterized enterobacterial phosphate (Pho) regulon (see Rao \& Torriani, 1990). Aiba et al. (1993) cloned a chromosomal fragment from Synechococcus sp. PCC 7942 which was able to phenotypically complement a double mutant of $E$. coli that had lesions in the $p b o \mathrm{R}$ and $\mathrm{cre} C$ (histidine protein kinases) genes and was phenotypically $\mathrm{PhoA}^{-}$(alkaline phosphatase negative) as a consequence of being unable to induce the phosphate regulon. The cloned fragment carried two genes, designated $s p h S$ and $s p h R$, encoding polypeptides which, respectively, exhibited strong similarities to the histidine protein kinase and response regulator families of proteins. A purified truncated version of SphS exhibited autophosphorylation activity consistent with its identification as a histidine protein kinase. Deletion mutants of Synechococcus sp. PCC 7942 lacking both $s p h S$ and $s p b R$ failed to induce several 
proteins in response to phosphate limitation that were observed with the wild-type, and also failed to induce significant alkaline phosphatase activity. More recently, Nagaya et al. (1994) have shown that purified SphR is phosphorylated by phosphotransfer from SphS and binds to two distinct sites upstream from the alkaline phosphatase promoter, thus establishing their unambiguous identification as a histidine protein kinase/response pair. Similar evidence has been obtained with a phycoerythrincontaining marine strain, Synechococcus sp. WH7803. Two closely linked ORFs exhibiting high similarities ( $41 \%$ and $26 \%$ identity, respectively) to PhoP of B. subtilis and PhoR of E. coli have been characterized, and transcription of these genes was markedly increased under conditions of phosphate limitation (G. M. F. Watson, this laboratory - unpublished results).

A second similarity with the Pho regulon was established with Synechococcus sp. WH7803. This strain has been shown to contain a gene ( $p$ st $S$ ) encoding a presumptive periplasmic phosphate-binding protein which is transcribed under conditions of phosphate limitation (Scanlan et al., 1993). No homologue of the pstS gene could be detected in freshwater cyanobacterial strains, nor could the PstS protein be detected immunologically. However, Aiba \& Mizuno (1994) recently described a $33 \mathrm{kDa}$ protein, under the control of SphS/R, which was induced in Synechococcus sp. PCC 7942 by phosphate limitation. Sequence analysis of the cloned gene $\operatorname{sph} X$ revealed an ORF of 337 amino acids which had a putative bacterial-signal-like sequence at the $\mathrm{N}$-terminus. Wagner et al. (1994) reported the induction in the freshwater cyanobacterium Anacystis nidulans (Synechococcus species) strain 1402-1 of a polypeptide with an apparent size of $28-35 \mathrm{kDa}$ in response to phosphate-limited growth which appeared to localize to the cytoplasmic membrane. The protein, which was described as a high affinity phosphate-binding protein, could be functionally reconstituted into liposomes. Amino-terminal sequence analyses of tryptic fragments of the protein were carried out and the two sequences reported, SFVNFYLQNA and VYAPGTDSGTYDYFNEAILNK, are identical to two regions of SphX. Mann \& Scanlan (1994) have proposed that SphX and PstS are related and are both members of a family of phosphate-binding proteins. Thus it seems that the cyanobacterial response to phosphate limitation involves a system bearing marked similarities to the enterobacterial Pho regulon and that the regulation of expression of the proteins involved in the response is under the control of phosphorylation of a response regulator protein.

\section{Chemotaxis}

Many cyanobacteria have been shown to exhibit chemotactic responses, and Morgan et al. (1993) have demonstrated the presence of proteins antigenically related to the methyl-accepting chemotaxis proteins of $E$. coli in Synechocystis sp. PCC 6803 and Oscillatoria tenuis. The pat $A$ gene product of Anabaena sp. PCC 7120 shows marked homology in its carboxyl-terminal domain to the response regulator chemotaxis protein $\mathrm{CheY}$; however, pat $A$ is involved in the control of heterocyst pattern formation (Liang et al., 1992). Recently though, sequence analysis of a genomic fragment from the phycoerythrincontaining marine strain Synechococcus sp. WH7803 revealed two ORFs for which the predicted translation products exhibited very high homologies to CheA and a methyl-accepting chemotaxis protein (G. M. F. Watson, this laboratory - unpublished results), suggesting that at least this strain may possess a phosphorylation-dependent signal transduction pathway related to chemotaxis. Waterbury et al. (1985) have shown that several of the marine phycoerythrin-containing Synechococcus strains are capable of a swimming motility which is thought to enable them to respond chemotactically to nutrientenriched micropatches.

\section{General stress responses}

\section{Salinity}

The one general stress response in cyanobacteria in which protein phosphorylation has been implicated is that of salt stress (Hagemann et al., 1993). Both hyper- and hypoosmotic salt shocks led to very rapid alterations in the in vivo patterns of protein phosphorylation in cultures of Synechocystis sp. PCC 6803. These effects seem to be specific to $\mathrm{NaCl}$ since they could not be achieved with glycerol at the same osmotic concentration. Similarly, alterations in the pattern of phosphorylation were detected in vitro using either extracts of salt-shocked cells or upon addition of salt to extracts from unshocked cells. There is no information regarding the localization or identity of the phosphorylated species. The adaptation to salt stress in Synechocystis sp. PCC 6803 involves a diminished energy transfer from the phycobilisomes to PSII (Schubert \& Hagemann, 1990) and in that sense resembles a state transition. Moreover, this process of adaptation involves increases in electron transport rates involving both PSI and cytochrome oxidase activity (Jeanjean et al., 1990). Thus, the evidence that protein phosphorylation is involved mechanistically in these changes is only correlative.

\section{Two-component sensory systems}

Sensory transduction pathways involving two highly conserved families of proteins, histidine protein kinases and response regulators, have been extensively characterized from many genera of bacteria and are involved in adaptive responses to an enormously wide range of environmental variables (for reviews see Stock $e t$ al., 1989; Parkinson \& Kofoid, 1992). Several genes have been characterized from cyanobacteria which appear to encode polypeptides that exhibit marked sequence similarities to either the histidine protein kinase or response regulator families of proteins (see Table 1). Some of these genes have already been mentioned, i.e. in the case of phosphate acquisition and chromatic adaptation. In addition, Schluchter \& Bryant (1992) have described an incomplete ORF downstream from the petH (ferredoxin-NADP ${ }^{+}$oxidoreductase) gene of Synechococcus 
Table 1. Cyanobacterial genes and ORFs encoding putative members of the histidine protein kinase or response regulator families of two component sensory systems

\begin{tabular}{|c|c|c|c|c|c|c|}
\hline Organism & $\begin{array}{c}\text { Gene } \\
\text { or ORF } \\
\text { designation }\end{array}$ & $\begin{array}{l}\text { Predicted/observed } \\
\text { size of polypeptide } \\
\text { (amino acids) }\end{array}$ & $\begin{array}{l}\text { Histidine } \\
\text { protein } \\
\text { kinase/response } \\
\text { regulator }\end{array}$ & Homologies & $\begin{array}{l}\text { Suggested } \\
\text { function }\end{array}$ & $\begin{array}{l}\text { Reference/source/ } \\
\text { accession number }\end{array}$ \\
\hline Fremyella diplosiphon & $r c a C$ & 632 & $\mathrm{RR}$ & PhoR B. subtilis & $\begin{array}{l}\text { Chromatic } \\
\text { adaptation }\end{array}$ & $\begin{array}{l}\text { Chiang et al. (1992) } \\
\text { S27576 }\end{array}$ \\
\hline \multirow{2}{*}{$\begin{array}{l}\text { Synechocystis sp. } \\
\text { PCC } 6803\end{array}$} & $d f r A$ & 663 & $\mathrm{HPK}$ & PhoR B. subtilis & - & X72856 \\
\hline & ORF & 153 & RR & PhoP B. subtilis & - & Chitnis et al. (1989) \\
\hline Synechococcus sp. & $s p h S$ & 415 & $\mathrm{HPK}$ & PhoR B. subtilis & Pho regulon & Aiba et al. (1993) \\
\hline \multirow[t]{4}{*}{ PCC 7942} & $\operatorname{sphR}$ & 257 & $\mathrm{RR}$ & PhoP B. subtilis & Pho regulon & D13172 \\
\hline & $\operatorname{sas} A$ & 387 & HPK & RcsC E. coli & - & Nagaya et al. (1993) \\
\hline & $\operatorname{sr} A$ & 516 & $\mathrm{RR}$ & OmpR rhodophyte & & $\begin{array}{l}\text { Anandan et al. (1993) } \\
\text { and S. S. Golden }\end{array}$ \\
\hline & $s r r B$ & 237 & $\mathrm{RR}$ & OmpR rhodophyte & & $\begin{array}{l}\text { (personal } \\
\text { communication) }\end{array}$ \\
\hline $\begin{array}{l}\text { Synechococcus sp. } \\
\text { PCC } 7002\end{array}$ & ORF & Incomplete & $\mathrm{RR}$ & ArcA (dye) E. coli & - & $\begin{array}{l}\text { Schluchter \& Bryant } \\
\text { (1992) JO5366 }\end{array}$ \\
\hline Synechococcus sp. & phoR & 383 & HPK & PhoR B. subtilis & Pho regulon & G. M. F. Watson \\
\hline \multirow[t]{2}{*}{ WH7803 } & $p h o B$ & 234 & RR & PhoP B. subtilis & Pho regulon & (unpublished \\
\hline & ORF & Incomplete & HPK & CheA E. coli & Chemotaxis & $\begin{array}{l}\text { results; this } \\
\text { laboratory) }\end{array}$ \\
\hline $\begin{array}{l}\text { Anabaena sp. PCC } \\
7120\end{array}$ & pat $A$ & 379 & $\mathrm{RR}$ & CheY E. coli & $\begin{array}{l}\text { Heterocyst } \\
\text { pattern }\end{array}$ & Liang et al. (1992) \\
\hline
\end{tabular}

sp. PCC 7002 which encodes a polypeptide with $32-42 \%$ similarity to the response regulators $\mathrm{RscC}$, PhoB, the dye-resistance protein, and SprA. Shestakov et al. (1993) have described the isolation of a mutant of Synechocystis sp. PCC 6803 resistant to the herbicide difunon which is simultaneously resistant to chlorpromazine. Sequence analysis showed the mutation to affect a large ORF (663 amino acids) potentially encoding a polypeptide (Dfr) of $74.5 \mathrm{kDa}$ and the construction of insertion mutations in this ORF gave rise to strains which were difunon resistant. The C-terminal end of Dfr exhibits considerable homology with PhoR of $B$. subtilis and therefore may be the histidine protein kinase element of a two-component sensory system. Nagaya et al. (1993), using a similar approach to that of Aiba et al. (1993), have cloned a gene, designated sas $A$, from Synechococcus sp. PCC 7942 which at high copy number is able to complement lesions in an $e n v Z$ mutant of $E$. coli and also in a phoR cre $C$ double mutant. The sas $A$ gene encodes a polypeptide of 387 amino acids which exhibits autophosphorylation and appears to be a member of the histidine protein kinase family with particular similarity to RcsC, EnvZ and PhoR of E. coli. It is interesting to note that the $N$-terminal domain of Sas A lacks any significant potential membrane-spanning domains and therefore may be cytoplasmic. Two further genes, $s s r A$ and $s s B$, have been isolated from Synechococcus sp. PCC 7942, both of which appear to encode response regulators (Anandan et al., 1993). SsrA appears to have an extra $\mathrm{N}$-terminal domain in addition to the typical $\mathrm{C}$ - terminal response regulator domain (S. S. Golden, personal communication). The large endogenous plasmid of Synechococcus sp. PCC 7942 also appears to encode a histidine protein kinase response regulator pair (D. Laudenbach, personal communication). Finally, Chitnis et al. (1989) have found an ORF immediately upstream from the PSI gene $p s a E$ which potentially encoded a protein with considerable similarity to the $B$. subtilis response regulator PhoP. However, the ORF was transcribed from the opposite strand to $p s a E$.

\section{Other protein kinases and phosphatases}

Whilst there has been progress in analysing the physiological role of histidine protein kinases, particularly with respect to phosphate acquisition, comparatively little has been established about the nature of the kinase and phosphatases involved in determining the phosphorylation states of proteins which are subject to phosphorylation as monoesters. This is despite the fact that several species of cyanobacteria, including Synecbococcus sp. PCC 6301 (Allen et al., 1985), Calothrix sp. PCC 7601 (Schuster et al., 1984), Anabaena sp. PCC 7120 (Mann et al., 1991) and Synechocystis sp. PCC 6803 (Bloye et al., 1992), have been shown, directly or indirectly, to contain a number of proteins which are subject to phosphorylation via the formation of monoesters with the hydroxyl-containing amino acids serine, threonine and tyrosine. Using an approach initially developed with Myxococcus xanthus, 
Zhang (1993) has characterized a gene $(p k n A)$ from Anabaena sp. PCC 7120 which encodes a protein containing marked similarities in amino acid sequence to the catalytic domain of the eukaryotic serine/threonine protein kinases. As in the case of M. xanthus, it would appear that there is a cyanobacterial family of related kinases. Inactivation of the gene led to a pleiotropic phenotype which included a reduced heterocyst frequency under $\mathrm{N}_{2}$ fixing conditions. Mention has already been made of the putative protein-ty rosine-phosphatase-encoding ORF adjacent to the genes encoding the major phycobilisome rod components in Synechococcus sp. WH8020 (Wilbanks \& Glazer, 1993) and to the possible serine/threonine protein kinase of $F$. diplosiphon (Grossman et al., 1993). A polypeptide of approximately $60 \mathrm{kDa}$ associated with the thylakoids of Synechocystis sp. PCC 6803 is immunologically cross-reactive to antiserum raised against a preparation of higher plant LHCII kinase (unpublished results - this laboratory). Potts et al. (1993) have characterized a gene, designated ihpP, from Nostoc commune UTEX 584, encoding a polypeptide of approximately $30 \mathrm{kDa}$ (294 amino acids), which included a sequence motif characteristic of certain protein tyrosine phosphatases from eukaryotes. The ihp $P$ gene, on expression in E. coli, yields a protein with both tyrosine and serine phosphatase activities against artificial substrates. Somewhat surprisingly the amino acid sequence predicted for the $i h p P$ gene product includes at its amino terminus a sequence of 24 amino acids which constitute a potential signal sequence, and indeed the gene when expressed in E. coli does appear to give rise to an extracellular product. Potts et al. (1993) also demonstrated by immunoblotting the presence of a tyrosine phosphorylated protein of approximately $85 \mathrm{kDa}$ in $N$. commune grown in the presence of combined nitrogen which was not detectable after growth in nitrogen-deficient media. However, if the IhpP protein is also subject to secretion in $N$. commune it is difficult to reconcile this with the protein having a role in the regulation of nitrogen metabolism and perhaps it functions rather in phosphate nutrition. Sim \& Mudge (1993) report that naturally occurring cyanobacterial scums containing predominantly Anabaena circinalis produced significant amounts of a glycogen phosphorylase phosphatase activity.

The activities of several of the protein kinases and phosphatases in cyanobacteria can be modulated by metabolites at physiologically significant concentrations and other factors such as the redox potential. The phosphorylation state of several Synechococcus sp. PCC 6301 thylakoid proteins is determined by redox conditions, in particular the redox state of plastoquinone (and/or the cytochrome $b_{6} / f$ complex) (see Allen, 1992). In the case of Anabaena sp. PCC 7120, glucose 6-phosphate and ribulose 5-phosphate modulated the phosphorylation state of a $56 \mathrm{kDa}$ protein by respectively stimulating a phosphatase and inhibiting a kinase, and the phosphorylation of other proteins could be affected by dithiothreitol (Mann et al., 1991). Similarly, glucose 6phosphate and ribulose 5-phosphate are key effectors, together with $\mathrm{NAD}^{+} / \mathrm{NADH}$ and $\mathrm{NADP}^{+} / \mathrm{NADPH}$, of the two thylakoid-associated protein kinases of Synechocystis sp. PCC 6803 (unpublished results - this laboratory). In the case of these two kinases the redox state of plastoquinone and/or the cytochrome $b_{6} / f$ complex was also an effector of activity.

\section{Comments}

It is clear that protein phosphorylation plays a role in several key aspects of cyanobacterial physiology and that two-component sensory systems are implicated in several of these areas. However, it now seems possible that protein phosphorylation may be involved in the overall integration of metabolism. Cyanobacteria must respond not only to changes in light quality and quantity which will affect the relative production of ATP and NADPH, but also to changing metabolic demands for energy and reductant and indeed to the switch between dark respiratory metabolism and light photosynthetic metabolism. Thus, growth under conditions of low $\mathrm{C}_{\mathrm{i}}$ availability would lead to increased requirement for ATP, while growth on nitrate as a nitrogen source would lead to increased requirement for reductant. Consequently, the cell must regulate its photosynthetic activity, both in terms of absolute rate and of the pathways of photosynthetic electron flow (linear, cyclic and pseudocyclic). In the longer term the adaptation process may rely, at least in part, on changes in the pattern of transcription. For example in the case of persistent shifts in light quality, the stoichiometry of PSI/PSII in the thylakoids is altered by adjusting the absolute amounts of PSI (see Murakami \& Fujita, 1993). Protein phosphorylation is likely to be involved in the short-term adaptive responses that permit balanced metabolism prior to the transcriptional adaptation or where the environmental parameter varies over time-scales too short for transcriptional responses. Evidence has already been described for short-term changes in the pattern of protein phosphorylation in response to such factors as $C_{i}$ availability, light quality, nitrogen source, salt stress, etc. and in some of these cases the changes in the pattern of phosphorylation have been shown to involve thylakoidassociated proteins. Thus, it is tempting to speculate that the thylakoids are not just involved in regulating state transitions but are the site of metabolic integration for a range of disparate signals and that the mechanism involved in integration is protein phosphorylation. This being the case, the thylakoid-associated protein kinases would need to be sensitive to a wide range of metabolic factors which would include the redox state of photosynthetic electron transport pathway components, the energy charge, the redox state of the pyridine nucleotide pools, and the concentration of key metabolites of photosynthetic and respiratory metabolism. Such a degree of versatility is seen in the range of signals responded to by the isocitrate dehydrogenase kinase/phosphatase of E. coli (see Holms, 1986). There is some evidence to support this notion of the phosphorylation of thylakoid-associated proteins being a key process in metabolic integration. The redox control of protein phosphorylation in cyanobacterial cell-free 
extracts has been reported (Mann et al., 1991) and this is also true for partially purified thylakoid systems (see Allen, 1992). Furthermore, the regulation of protein phosphorylation by key metabolites of photosynthetic: and dark respiratory metabolism, in particular ribulose 5 phosphate and glucose 6-phosphate, has been detected in cell-free extracts of Anabaena sp. PCC 7120 and partially purified thylakoids from Synechocystis sp. PCC 6803 (unpublished results - this laboratory). In vivo studies on protein phosphorylation in Synechocystis sp. PCC6803 showed that the protein phosphorylation profile of cells growing under conditions of low $C_{i}$ availability were altered in the same fashion by three distinct environmental changes, i.e. increase in $C_{i}$ availability, addition of exogenous glucose and transfer into the dark (Bloye et al., 1992). The majority of these proteins were membrane associated. The phosphorylation state of the $\mathrm{G} \ln B$ protein involved in controlling nitrogen metabolism is responsive, at least in some strains, to the spectral quality of the incident light (Tsinoremas et al., 1991; Forchhammer \& Tandeau de Marsac, 1994). This model for metabolic integration emphasizes the importance of identifying cyanobacterial thylakoid-associated proteins and characterizing the kinases and phosphatases that determine their phosphorylation state.

\section{Acknowledgements}

NHM would like to thank Susan Golden and David Laudenbach for contributing unpublished information and colleagues, including Nigel Silman, Greg Watson, Noel Carr and John Allen, for constructive criticism of the manuscript. The work described from this laboratory was supported by grants from the AFRC and NERC.

\section{References}

Aiba, H. \& Mizuno, T. (1994). A novel gene whose expression is regulated by the response-regulator, $\mathrm{SphR}$, in response to phosphate limitation in Synechococcus species PCC7942. Mol Microbiol 13, 25-34.

Aiba, H., Nagaya, M. \& Mizuno, T. (1993). Sensor and regulator proteins from the cyanobacterium Synechococcus species PCC 7942 that belong to the bacterial signal-transduction protein families: implication in the adaptive response to phosphate limitation. Mol Microbiol 8, 81-91.

Allen, J. F. (1992). Protein phosphorylation in regulation of photosynthesis. Biochim Biophys Acta 1098, 275-335.

Allen, J. F., Sanders, C. E. \& Holmes, N. G. (1985). Correlation of membrane protein phosphorylation with excitation energy distribution in the cyanobacterium Synechococcus 6301. FEBS Lett 193, 271-275.

Anandan, S., Nalty, M. S., Snodgrass, P., Cogdell, D. E. \& Golden, S. S. (1993). Identification and cloning of putative two-component system response regulator genes in Synechococcus sp. strain PCC 7942. The Cyanobacterial Workshop Abstracts, 12.

Badger, M. R. (1987). The $\mathrm{CO}_{2}$ concentrating mechanism in aquatic phototrophs. In The Biochemistry of Plants: A Comprehensive Treatise, vol. 10, pp. 219-274, Photosynthesis. Edited by M. D. Hatch \& K. Boardman. New York: Academic Press.

Bloye, S. A., Silman, N. J., Mann, N. H. \& Carr, N. G. (1992). Bicarbonate concentration by Synechocystis PCC6803: modulation of protein phosphorylation and inorganic carbon transport by glucose. Plant Physiol 99, 601-606.

Chiang, G. C., Schaefer, M. R. \& Grossman, A. R. (1992). Complementation of a red light-indifferent cyanobacterial mutant. Proc Natl Acad Sci US A 89, 9415-9419.

Chitnis, P. R., Reilly, P. A., Miedel, M. C. \& Nelson, N. (1989). Structure and targeted mutagenesis of the gene encoding $8-\mathrm{kDa}$ subunit of photosystem I from the cyanobacterium Synechocystis sp. PCC 6803. J Biol Chem 264, 18374-18380.

Falkner, G., Falkner, R. \& Schwab, A. (1989). Bioenergetic characterization of transient state phosphate uptake by the cyanobacterium Anacystis nidulans. Arch Microbiol 152, 353-361.

Forchhammer, K. \& Tandeau de Marsac, N. (1994). The $P_{\text {II }}$ protein in the cyanobacterium Synechococcus sp. strain PCC 7942 is modified by serine phosphorylation and signals the cellular N-status. $J$ Bacteriol 176, 84-91.

Grossman, A. R., Schaefer, M. R., Chiang, G. G. \& Collier, J. L. (1993). The phycobilisome, a light-harvesting complex responsive to environmental conditions. Microbiol Rev 57, 725-749.

Hagemann, M., Golldack, D., Biggins, J. \& Erdmann, N. (1993). Salt-dependent protein phosphorylation in the cyanobacterium Synechocystis sp. PCC 6803. FEMS Microbiol Lett 113, 205-210.

Harrison, M. A. (1990). Molecular mechanisms of adaptation in the photosynthetic apparatus. $\mathrm{PhD}$ thesis, University of Leeds.

Holms, W. H. (1986). The central metabolic pathways of Escherichia coli: relationship between flux and control at a branch point, efficiency of conversion to biomass, and excretion of acetate. Curr Top Cell Regul 28, 69-105.

James, C. A., Peace, E. A. \& Evans, E. H. (1992). Phosphorylation patterns from thylakoid peptides from Synechococcus 7942 under nitrogen repleted and depleted conditions. Biocbem Soc Trans 21, 3 S.

Jeanjean, R., Onana, B., Peschek, G. A. \& Joset, F. (1990). Mutants of the cyanobacterium Synechocystis PCC6803 impaired in respiration and unable to tolerate high salt concentrations. FEMS Microbiol Lett 68, 125-130.

Liang, J., Scappino, L. \& Haselkorn, R. (1992). The pat $A$ gene product, which contains a region similar to $\mathrm{CheY}$ of Escberichia coli, controls heterocyst pattern formation in the cyanobacterium Anabaena 7120. Proc Natl Acad Sci US A 89, 5655-5659.

Magasanik, B. (1988). Reversible phosphorylation of an enhancer binding protein regulates the transcription of bacterial nitrogen utilization genes. Trends in Biol Sci 13, 475-479.

Mann, N. H. \& Scanlan, D. J. (1994). The SphX protein of Synechococcus species PCC 7942 belongs to a family of phosphate binding proteins. Mol Microbiol (in press).

Mann, N. H., Rippka, R. \& Herdman, M. (1991). Regulation of protein phosphorylation in the cyanobacterium Anabaena strain PCC 7120. J Gen Microbiol 137, 331-339.

Miller, A. G. (1990). Inorganic carbon transport and accumulation in cyanobacteria. In Advances in Autotrophic Microbiology and One Carbon Metabolism, vol. 1, pp. 25-33. Edited by G. A. Codd, L. Dijkhuizen \& F. R. Tabita. The Netherlands: Kluwer Academic Publishers.

Miller, A. G. \& Canvin, D. T. (1987). $\mathrm{Na}^{+}$-stimulation of photosynthesis in the cyanobacterium Synechococcus UTEX 625 grown on high levels of inorganic carbon. Plant Physiol 84, 118-124.

Miller, A. G., Espie, G. S. \& Canvin, D. T. (1988). Active transport of $\mathrm{CO}_{2}$ by the cyanobacterium Synechococcus UTEX 625. Plant Pbysiol 86, 677-683.

Morgan, D. G., Baumgartner, J. W. \& Hazelbauer, G. L. (1993). Proteins antigenically related to methyl-accepting chemotaxis 
proteins of Escherichia coli detected in a wide range of bacterial species. J Bacteriol 175, 133-140.

Murakami, A. \& Fujita, Y. (1993). Regulation of stoichiometry between PSI and PSII in response to light regime for photosynthesis observed with Synechocystis PCC 6714: relationship between redox state of $\mathrm{cyt}_{6} b_{6}-f$ complex and regulation of PSI formation. Plant Cell Physiol 34, 1175-1180.

Nagaya, M., Aiba, H. \& Mizuno, T. (1993). Cloning of a sensorykinase-encoding gene that belongs to the two-component regulatory family from the cyanobacterium Synecbococcus sp. PCC7942. Gene 131, 119-124.

Nagaya, M., Aiba, H. \& Mizuno, T. (1994). The $s p h$ R product, a two-component system response regulator protein, regulates phosphate assimilation in Synechococcus sp. strain PCC 7942 by binding to two sites upstream from the pho $A$ promoter. $J$ Bacteriol 176, $2210-2215$

Parkinson, J. S. \& Kofoid, E. C. (1992). Communication modules in bacterial signaling proteins. Annu Rev Genet 26, 71-112.

Pierce, J. \& Omata, T. (1988). Uptake and utilization of inorganic carbon by cyanobacteria. Photosynth Res 16, 141-154.

Potts, M., Sun, H., Mockaitis, K., Kennelly, P. J., Reed, D. \& Tonks, N. K. (1993). A protein-tyrosine/serine phosphatase encoded by the genome of the cyanobacterium Nostoc commune UTEX 584. J Biol Chem 268, 7632-7635.

Race, H. L. \& Gounaris, K. (1993). Identification of the $p s b H$ gene product as a $6 \mathrm{kDa}$ phosphoprotein in the cyanobacterium Synechocystis 6803. FEBS Lett 323, 35-39.

Rao, N. N. \& Torriani, A. (1990). Molecular aspects of phosphate transport in Escherichia coli. Mol Microbiol 4, 1083-1090.

Romero, J. M. \& Lara, C. (1987). Photosynthetic assimilation of $\mathrm{NO}_{3}^{-}$by intact cells of the cyanobacterium Anacystis nidulans. Plant Pbysiol 83, 208-212.

Romero, J. M., Lara, C. \& Sivak, M. N. (1992). Effect of carbon and nitrogen assimilation on chlorophyll fluorescence emission by the cyanobacterium Anacystis nidulans. Physiol Plant 85, 433-438.

Sanders, C. E. \& Allen, J. F. (1987). The $18.5 \mathrm{kDa}$ phosphoprotein of the cyanobacterium Synechococcus 6301: a component of the phycobilisome. In Progress in Photosynthesis Research, vol. II, pp. 761-764. Edited by J. Biggins. Dordrecht, The Netherlands: Martinus Nijhoff.

Sanders, C. E., Melis, A. \& Allen, J. F. (1989). In vivo phosphorylation of proteins in the cyanobacterium Synechococcus 6301 after chromatic acclimation to photosystem I or photosystem II light. Biocbim Biophys Acta 976, 168-172.

Scanlan, D. J., Mann, N. H. \& Carr, N. G. (1993). The response of the picoplanktonic marine cyanobacterium Synechococcus sp. WH7803 to phosphate starvation involves a protein homologous to the periplasmic phosphate-binding protein of Escherichia coli. Mol Microbiol 10, 181-191.

Schluchter, W. M. \& Bryant, D. A. (1992). Molecular characterization of ferredoxin-NADP ${ }^{+}$oxidoreductase in cyanobacteria: cloning and sequence of the $p e t \mathrm{H}$ gene of Synechococcus sp. PCC 7002 and studies on the gene product. Biochemistry 31, 3092-3102.
Schmidt-Goff, C. M. \& Federspiel, N. A. (1993). In vivo and in vitro footprinting of a light-regulated promoter in the cyanobacterium Fremyella diplosiphon. J Bacteriol 175, 1806-1813.

Schubert, H. \& Hagemann, M. (1990). Salt effects of $77 \mathrm{~K}$ fluorescence and photosynthesis in the cyanobacterium Synechocystis sp. PCC 6803. FEMS Microbiol Lett 71, 169-172.

Schuster, G., Owens, G. C., Cohen, Y. \& Ohad, I. (1984). Thylakoid polypeptide composition and light-independent phosphorylation of the chlorophyll $a, b$ protein in Prochloron, a prokaryote exhibiting oxygenic photosynthesis. Biochim Biopbys Acta 767, 596-605.

Shestakov, S., Chesnavichene, E., Bartsevich, V. \& Elanskaya, I. (1993). Molecular characterization of genes controlling resistance to herbicides in the cyanobacterium Synecbocystis 6803. The Cyanobacterial Workshop Abstracts, 86.

Sim, A. T. R. \& Mudge, L. M. (1993). Protein phosphatase activity in cyanobacteria: consequences for microcystin toxicity analysis. Toxicon 31, 1179-1186.

Sobczyk, A. (1994). Caratérisation d'effecteurs transcriptionnels impliqués dans la regulation de l'adaptation chromatique complémentaire chez la cyanobacterie Calothrix PCC 7601. PhD thesis, University of Paris.

Sobczyk, A., Schyns, G., Tandeau de Marsac, N. \& Houmard, J. (1993). Transduction of the light signal during complementary chromatic adaptation in the cyanobacterium Calotbrix sp. PCC 7601 : DNA-binding proteins and modulation by phosphorylation. EMBO J 12, 997-1004.

Sobczyk, A., Bely, A., Tandeau de Marsac, N. \& Houmard, J. (1994). A phosphorylated DNA-binding protein is specific for the red light signal during complementary chromatic adaptation. Mol Microbiol (in press).

Stock, J. B., Ninfa, A. J. \& Stock, A. (1989). Protein phosphorylation and regulation of adaptive responses in bacteria. Microbiol Rev 53, 450-490.

Tandeau de Marsac, N. \& Houmard, J. (1993). Adaptation of cyanobacteria to environmental stimuli: new steps towards molecular mechanisms. FEMS Microbiol Rev 104, 119-190.

Tsinoremas, N. F., Castets, A. M., Harrison, M. A., Allen, J. F. \& Tandeau de Marsac, N. (1991). Photosynthetic electron transport controls nitrogen assimilation in cyanobacteria by means of posttranslational modification of the glnB gene product. Proc Natl Acad Sci US A 88, 4565-4569.

Wagner, F., Gimona, M., Ahorn, H., Peschek, G. A. \& Falkner, G. (1994). Isolation and functional reconstitution of a phosphate binding protein of the cyanobacterium Anacystis nidulans induced during phosphate limited growth. J Biol Chem 269, 5509-5511.

Waterbury, J. B., Willey, J. M., Franks, D. G., Valois, F. W. \& Watson, S. W. (1985). A cyanobacterium capable of swimming motility. Science 230, 74-76.

Wilbanks, S. M. \& Glazer, A. N. (1993). Rod structure of a phycoerythrin II-containing phycobilisome: I. Organization and sequence of the gene encoding the major phycobiliprotein rod components in the genome of the marine Synechococcus sp. WH8020. J Biol Chem 268, 1226-1235.

Zhang, C.-C. (1993). A gene encoding a protein related to eukaryotic protein kinases from the filamentous heterocystous cyanobacterium Anabaena PCC 7120. Proc Natl Acad Sci USA 90, 11840-11844. 